\section{Behavioral effects: Hippocampal destruction and scopolamine}

EVAN SUITS and ROBERT L. ISAACSON, University of Florida, Gainesville, Fla. 32601

Rats with sham, cortical, and hippocampal lesions were trained in one-way and two-way avoidance tasks while under the influence of scopolamine hydrobromide. The performance of the hippocampal-lesion group was worse than that of the sham-operate group on the one-way task but better on the two-way task. This demonstrates the efficiency of the lesion on drugged animals, despite the similarity of effects of both the lesions and the drug injections.

Many studies have demonstrated a striking similarity between the effects on behavior of hippocampal lesions and the administration of anticholinergic drugs. For example, in avoidance learning, Isaacson, Douglas, \& Moore (1961) and Olton \& Isaacson (1966) found that hippocampal lesions improved acquisition of a two-way avoidance task but impaired learning of a one-way avoidance task. Suits \& Isaacson (1968) found similar effects following scopolamine administration. Isaacson \& Wickelgren (1962) showed that hippocampal lesions disrupt passive-avoidance behavior, while Meyers (1965), Bohdanecky \& Jarvik (1967), and Suits \& Isaacson (1969) fround similar results due to scopolamine injection.

Other studies report the same similarity of effect of the two experimental manipulations. Both produce increases in activity (Tapp, 1965; Douglas \& Isaacson, 1964), perseveration of learned responses (Kimble \& Kimble, 1965; Hearst, 1959), and reduction of spontaneous alternation (Douglas \& Isaacson, 1966; Roberts, Dember, Brodwick, 1962).

The similarity of effects on behavior of the drugs and the lesions suggests that the hippocampus might be the site of action of the scopolamine. It was our general purpose to test this hypothesis by determining whether or not the previously determined lesion effects in the active-avoidance paradigm could be found in animals treated with scopolamine hydrobromide.

Two active avoidance tasks were selected both for their convenience and for their comparability with earlier work by the same authors (Suits \& Isaacson, 1968). This earlier study concerned the effects of scopolamine on one-way and two-way avoidance learning in rats. The present study utilized the identical avoidance procedure, but the one-way avoidance task had to be modified from that used in our previous study due to the extreme excitability, to be described below, of the Ss.

Twenty-seven albino rats were used in the one-way avoidance task and 18 albino rats were used in the two-way procedure. All Ss were between 100 and 200 days old at the beginning of the experiment. Animals used in both avoidance tasks were divided into three equal sized surgical groups: a group with damage limited to neocortex, a group in which the hippocampus and overlying cortex was removed, and a sham-operate group.

During surgery, Ss were anesthetized with sodium pentobarbital and the skulls exposed. Trephine holes were made bilaterally just posterior to bregma and the holes enlarged with rongeurs. At this point, Ss of the sham-operate groups had the scalp closed by sutures. For $S s$ in the neocortical-lesion group, dura was slit and the neocortex overlying the hippocampus removed by aspiration. The hippocampal group had both neocortex and hippocampus removed. Wounds were then packed with Gelfoam and the scalp sutured. All Ss were given tetracyclene in their drinking water for 2 days after the operation.

Following training, Ss were injected with a lethal dose of sodium pentobarbital and perfused intracardially with $0.9 \%$ saline followed by $10 \%$ formalin solution. The brains were removed, embedded in paraffin, and sectioned at 20 microns. Sections were then mounted on slides and stained with thionin. The stained sections were superimposed on appropriate diagrams of the rat brain, as provided by DeGroot (1959). A grid on the diagrams, composed of $0.5-\mathrm{cm}$ squares, was utilized to compute a numerical index of lesion size.

The training apparatus we used consisted of two independently movable grid-floored compartments, each measuring $5 \times 8 \times 9$ in., with guillotine-type doors above 2-in.high barriers at both ends. One compartment was painted inside with $1 / 2$-in.-wide black and white stripes oriented vertically, while the other compartment was painted with similar stripes oriented horizontally. The conditioned stimulus was a doorbell buzzer and the simultaneous raising of the guillotine door separating the compartments.

Prior to each training day, all Ss were weighed and injected with $1.0 \mathrm{mg} / \mathrm{kg}$ scopolamine hydrobromide from a solution of $0.4 \mathrm{mg} / \mathrm{ml}$, USP, and returned to the home cage for $30 \mathrm{~min}$. Drugs and training were given only on alternate days to reduce the possibility of cumulative effects of the drug.

Training in the two-way avoidance task was carried out in the same manner as reported before (Suits \& Isaacson, 1968). S was placed in the right-hand compartment. After $30 \mathrm{sec}$, the doors between the two compartments were raised, the buzzer turned on, a small overhead light in the compartment containing $S$ extinguished, and the light in the other compartment illuminated. If $\mathbf{S}$ did not cross over the barrier within $10 \mathrm{sec}$, it received $0.5-\mathrm{sec}$ shocks of $0.8 \mathrm{~mA}$, delivered at a rate of one per second. If $S$ crossed before the 10-sec CS-US interval, no shocks were delivered. The trial was ended when S's hind feet had crossed over the barrier, at which point the doors were closed, the buzzer turned off, and the latency of the trial recorded. $S$ ran in opposite directions on every other trial.

In the past, we had noted that both hippocampal lesions and drug treatment increased the general excitability of the animals. Within a few days after surgery, the excitability of the hippocampally damaged group dissipated. The combination of the drug and the hippocampal destruction, however, produced an excitability that made the animals almost unmanageable. In order to complete the experiment, a special type of one-way avoidance training procedure had to be adopted. A one-way task, modeled after one developed by McCleary (1966), in which the animals are not handled between trials, was substituted for the standard one-way task as reported in Suits \& Isaacson (1968). It was felt that this substitution was justified since it has been demonstrated that rats learn a one-way task in which they are replaced by hand

Table 1

Group Mean Triak to $9 / 20$ and $19 / 20$ Criteri

$\left.\begin{array}{ccc}\hline & 9 / 20 & 19 / 20 \\ \hline \text { McCleary } & & \\ \text { N } & 17.9 & 41.7 \\ \text { C } & 20.6 & 46.4 \\ \text { H } & 25.8 & 63.7\end{array}\right)$

$* p<.05 \quad * p<.01$ 
Figure 1

into the start compartment between trials and the "McCleary task" at similar rates and that animals with hippocampal damage are impaired on both (Olton \& Isaacson, 1968).

Training in the McCleary one-way task was begun, with the two experimental compartments placed end to end. The CS and the response was the same as that used in the two-way avoidance training. After each response, the positions of the compartments were reversed by moving the compartment containing the animal back to the original starting position and moving the former starting compartment to the "goal position."

The Ss in both tasks were run 20 trials per training day until a performance level of 19 a voidance responses in 20 consecutive trials was reached. A $30-\mathrm{sec}$ intertrial interval was maintained throughout the experiment. One $S$ in the neocortical-lesion group for the two-way task was found to have suffered moderate hippocampal damage and hence was grouped with the hippocampectomized Ss in the analysis of the behavioral and histological data.

Hippocampal damage in the hippocampal-lesion groups was found to be smaller than expected. Hippocampal destruction in the hippocampally lesioned animals trained in the "McCleary task" group averaged $35 \%$, while the average was $54 \%$ in the two-way avoidance task. Hippocampal damage in cortical and sham-operate groups was negligible.

It was intended that cortical damage in the neocortical-lesion groups should exceed that in the hippocampal-lesion groups in order to control for total amount of tissue removed. This was found to be the case for Ss in the two-way task, but the amount of neocortical damage of Ss in the McCleary task was slightly smaller in amount for animals with neocortical damage than for those with hippocampal destruction.

The most impressive finding of the experiment was that the animals with hippocampal lesions under scopolamine were extremely excitable. After injection with the drug, the Ss would react violently to being touched or handled by biting, scratching, and squealing. When at rest or in their home cages, they seemed only slightly more active than the other Ss but, when picked up again, would resume their resistance and overreaction to handling. This hyperreactivity did not decrease with time, handling, or training.

The overreactivity and aggressiveness of the animals caused us to use the special McCleary type of one-way avoidance task

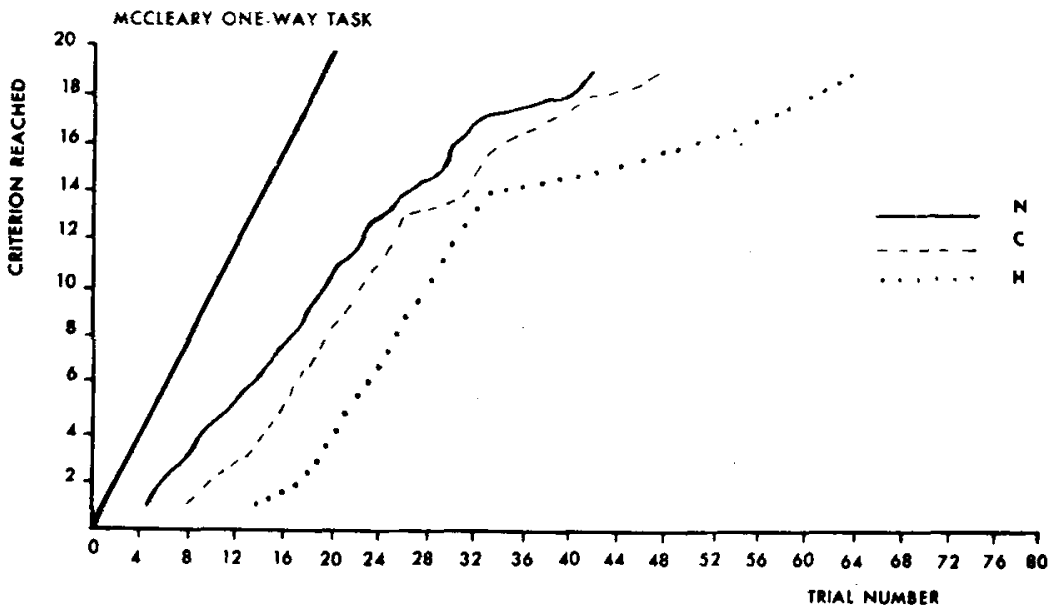

in place of the more traditional procedures, as mentioned above.

Group mean trials-to-criterion response rates of both 9 and 19 avoidance responses out of 20 trials were calculated and T tests performed on the group mean comparisons. ${ }^{2}$ The results are presented in tabular form in Table 1 and in graphic form in Figs. 1 and 2.

In the McCleary-style one-way task, the sham-operate group learned the problem fastest and the hippocampal-lesion group slowest, with the neocortical-lesion group falling in between. The scores were not greatly different, however, and the only statistically significant difference $(p<.05)$ among the scores was between the hippocampal and sham-operate groups in attaining the $19 / 20$ criterion.

In the two-way problem, the group order is reversed, with the hippocampal-lesion group reaching both criteria in about half the number of trials required by the sham operates, with the cortical-lesion group again falling in between. In reaching $9 / 20$, the sham-operate $S$ s were significantly $(p<.01)$ slower than both the corticaland hippocampal-lesion groups, with no significant difference between the latter two groups. In reaching $19 / 20$, the hippocampal-lesion group was significantly $(\mathrm{p}<.01)$ faster than either the cortical or sham-operate groups, with no differences in the performance of the latter two groups.

It is apparent from these data that hippocampal lesions produce similar effects in both normal and drugged rats. As both drug and lesion treatments produce similar results, the above data lead to certain inferences about the action of the drug.

First, it is unlikely that the drug acts by depressing the task-related functions of the hippocampus, despite the similarity of effects produced by the two treatments, for, if this were so, then the lesion of the hippocampus should be without effect. In other words, if the drug prevents the hippocampus from functioning relative to the tasks employed, then removal of the hippocampus should be without behavioral effect. It is also possible that the drug causes a partial loss of hippocampal function, and there is electrophysiological evidence which suggests this may be so (Stumpf, 1965). In this case, a lesion could produce behavioral effects. The evidence

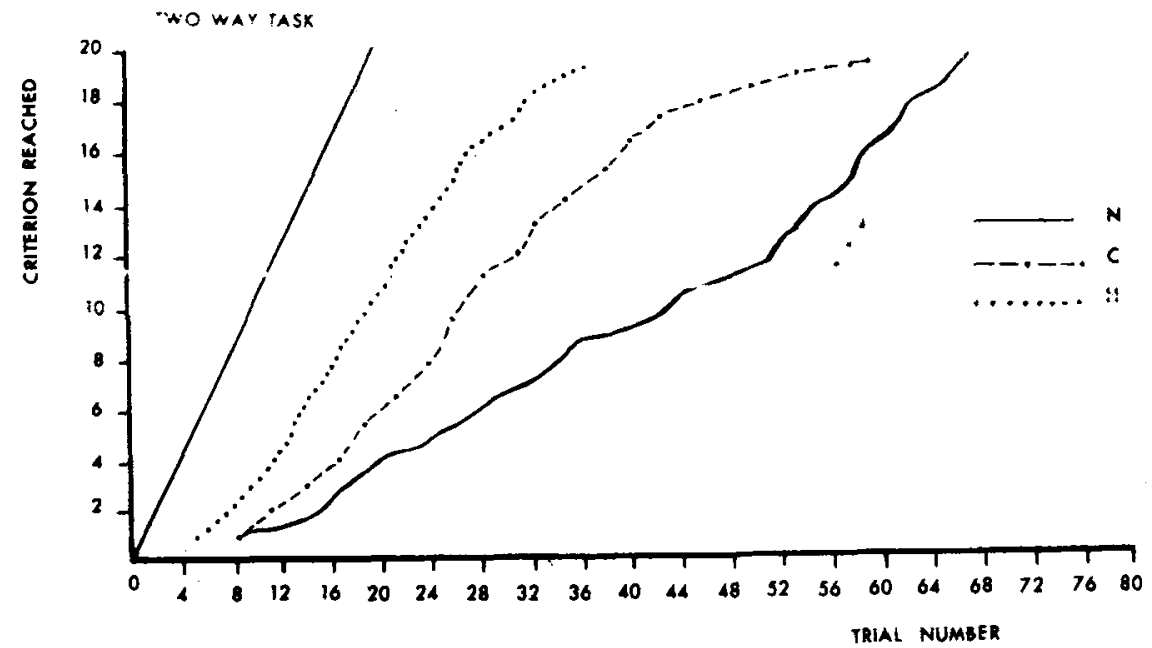

Figure 2 
for this partial blockage is not conclusive, however, and, since increased drug doses give increased effects only up to a certain point (Stumph, 1965), this explanation seems doubtful.

Secondly, since about $50 \%$ of the hippocampus remained in the animals in the hippocampal-lesion groups in this study, it is possible that the drug could cause this remainder to function abnormally. If it is assumed that a lesion causes the remaining hippocampal tissue to function abnormally, the effects of the drug and the lesion could sum together to produce the effects seen here. This alternative could be tested by repeating the experiment with more complete hippocampal lesions.

Finally, it is possible that the two experimental treatments have their effects through parallel, but independent, systems. In this case, Ss with total hippocampal lesions would still be affected by the drug.

\section{REFERENCES}

BOHDANECKY, Z., \& JARVIK, M. E. Impairment of one-trial passive avoidance learning in mice by scopolamine, scopolamine methylbromide, and phsostigmine. International Journal of Neuropharmacology, 1967, 6, 217-222.

DeGroot, J. The rat forebrain in stereotaxic coordinates. Verhandelingen Der Koninklijke Nederlandse Akademie Van Wetenschappen, AFD, Natuurkunde, 1959, 52, 1-40.

DOUGLAS, R. J., \& ISAACSON, R. L. Hippocampal lesions and activity. Psychonomic Science, 1964, 1, 187-188.

DOUGLAS, R. J., \& ISAACSON, R. L. Spontaneous alternation and scopolamine. Psychonomic Science, 1966, 4, 283-284.

HEARST, E. Effects of scopolamine on discriminated responding in the rat. International Journal of Pharmacology \& Experimental Therapy, 1959, 126, 349-358.

ISAACSON, R. L., DOUGLAS, R. J., \& MOORE, R. Y. The effects of radical hippocampal ablation on acquisition of avoidance response. Journal of Comparative \& Physiological Psychology, 1961, 54, 625-628.

ISAACSON, R. L., \& WICKELGREN, W. C.
Hippocampal ablation and passive avoidance. Science, 1962, 138, 1104-1106.

KIMBLE, D. P., \& KIMBLE, R. J. Hippocampectomy and response perseveration in the rat. Journal of Comparative \& Physiological Psychology, 1965, 60, 474-476.

MCCLEARY, R. A. Response-modulating functions of the limbic system: Initiation and suppression. In E. Stellar and J. M. Sprague (Eds.), Progress in physiological psychology. New York: Academic Press, 1966. Pp. 209-272.

MEYERS, B. Some effects of scopolamine on a passive avoidance response in rats. Psych opharmacologia (Berlin), 1965, 6, 111-119.

OLTON, D. S., \& ISAACSON, R. L. The effect of training trials on passive avoidance deficits in the hippocampectomized rat. Psychonomic Science, 1966, 5, 419-420.

OLTON, D. S., \& ISAACSON, R. L. Importance of spatial location in active avoidance tasks. Journal of Comparative \& Physiological Psychology, 1968, 65, 535-539.

ROBERTS, W. W., DEMBER, W. N., \& BRODWICK, N. Alienation and exploration in rats with hippocampal lesions. Journal of Comparative \& Physiological Psychology, 1962, 55, 695-700.

STUMPF, C. Drug action on the electrical activity of the hippocampus. International Review of Neurobiology, 1965, 8, 77-138.

SUITS, E., \& ISAACSON, R. L. The effects of scopolamine hydrobromide on one-way and two-way avoidance learning in rats. International Journal of Neuropharmacology, $1968,7,441-446$

SUITS, E., \& ISAACSON, R. L. The effects of scopolamine hydrobromide on passive avoidance learning in rats. Psychonomic Scjence, 1969, 15, 135-137.

TAPP, J. T. Cholinergic mechanisms in operant responding. Journal of Comparative \& Physiological Psychology, 1965, 59, 469-472.

\section{NOTES}

1. This imvestigation was supported by a grant from the National Institute of Mental Health (NIH-MH-112-8502) to R. L. Isaacson.

2. Four Ss were discarded from the study due to their failure to begin making avoidance responses within 100 trials. These were: one from the one-way cortical group, two from the one-way hippocampal group, one from the two-way cortical group. The data from these Ss are not included in the results.

Weiss \& Strongman (1969) exposed rats to a rodified conditioned suppression procedure in which, superimposed upon a positively reinforced operant baseline, shocks occurred randomly throughout a warning tone rather than at its termination. Using this procedure, they noted brief bursts of bar-pressing responses following the delivery of each shock. They concluded that these response bursts were not related to food but represented "attack" or "aggression," similar to reports by Ulich \& Azrin (1962) and others of shockelicited aggressive behavior. Weiss and Strongman did note, however, that such postshock response bursts did not occur for control animals exposed to identical warning periods and shocks, but for whom bar pressing was never reinforced by food and, presumably, did not occur. The purpose of the present paper is to argue against the interpretation of their data offered by Weiss and Strongman and to offer an alternative explanation based on similar data.

There appear to be three main objections to the "aggression" explanation in its present form. First, Weiss and Strongman make little of the control group's failure to emit identical "attack" responses, other than to concede that the "... history of lever pressing for food was critical in the development of the response bursts $[1969$, p. 240$] . "$ It is strange that an aggressive response, supposedly reflexive (if their reference to Ulrich and Azrin's data is literal), would depend so critically upon a history of appetitive reinforcement.

Second, with regard to the similarity the authors suggest between elicited aggression in their experiment (bar-pressing) and that in the research of Ulrich and Azrin (stereotyped physical contact between Ss), it should be noted that, in addition to the obvious difference in topography of the behaviors, Ulrich and Azrin used a shock intensity 10 times greater than that of Weiss and Strongman $(2.00 \mathrm{~mA}$ vs $0.2 \mathrm{~mA}$ ). It is highly unlikely that physical stimuli of such different intensities would elicit similar behavior. In fact, it is debatable that such a relatively weak shock could elicit aggression in the sense that Ulrich and others have used the term.

\begin{abstract}
HANK DAVIS, Califormia State College, Los Angeles, Calif. 90032
\end{abstract}

Data from a recent conditioned suppression experiment by Weiss \& Strongman (1969) are reexamined to determine the basis for postshock response bursts. The present paper debates Weiss and Strongman's conclusion that such responding represents "attack" or aggressive behavior. Using data from other conditioned suppression studies, it is argued that postshock responding is Third, granted that Weiss and
controlled, not by aversive stimuli, but by Strongman's use of a single-organism the appetitive baseline schedule of situation limited the available "targets" for reinforcement. It is generated specifically aggressive behavior, it still remains to be by what are termed "second-order explained why the lever would be the only contingencies," reliable experimental target for the aggression of all five operations that emerge as artifacts of other experimental animals. The authors features of the experimental procedure and themselves have ruled out an interpretation often go undetected by $E$. A functional based on superstitious avoidance relationship is proposed between the responding. This leaves only two degree of "safety" (absence of suppression) alternatives: (1) pure coincidence (i.e., all and presence of postshock-response bursts. experimental animals simply chose the 